\title{
The current state of bioterrorist attack surveillance and preparedness in the US
}

This article was published in the following Dove Press journal:

Risk Management and Healthcare Policy

9 October 2014

Number of times this article has been viewed

\section{Oliver Grundmann}

Department of Medicinal Chemistry,

College of Pharmacy, University

of Florida, Gainesville, FL, USA

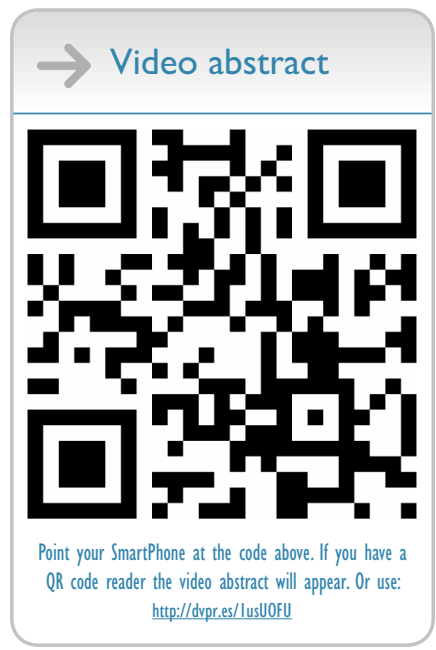

Correspondence: Oliver Grundmann Department of Medicinal Chemistry, College of Pharmacy, University of Florida, PO Box 100485, Gainesville, FL 32610, USA

Tel +l 3522464994

Fax +I 3523929455

Email grundman@ufl.edu
Abstract: The use of biological agents as weapons to disrupt established structures, such as governments and especially larger urban populations, has been prevalent throughout history. Following the anthrax letters sent to various government officials in the fall of 2001, the US has been investing in prevention, surveillance, and preparation for a potential bioterrorism attack. Additional funding authorized since 2002 has assisted the Centers for Disease Control and Prevention, the Department of Health and Human Services, and the Environmental Protection Agency to invest in preventative research measures as well as preparedness programs, such as the Laboratory Response Network, Hospital Preparedness Program, and BioWatch. With both sentinel monitoring systems and epidemiological surveillance programs in place for metropolitan areas, the immediate threat of a large-scale bioterrorist attack may be limited. However, early detection is a crucial factor to initiate immediate response measures to prevent further spread following dissemination of a biological agent. Especially in rural areas, an interagency approach to train health care workers and raise awareness for the general public remain primary tasks, which is an ongoing challenge. Risk-management approaches in responding to dissemination of biological agents, as well as appropriate decontamination measures that reduce the probability of further contamination, have been provided, and suggest further investments in preparedness and surveillance. Ongoing efforts to improve preparedness and response to a bioterrorist attack are crucial to further reduce morbidity, mortality, and economic impact on public health.

Keywords: bioterrorism, public health policy, risk management, community preparedness

\section{Introduction}

The past two decades have seen a significant rise in the use of biological agents for purposes of disseminating such substances to harm the public. Although commonly termed "bioterrorism", the purposes of such attacks are not necessarily intended to intimidate established government structures, but can also be motivated by religious, political, or ecological ideologies. ${ }^{1}$ Likewise, not all incidents involving actual or threatened dissemination of biological agents should be classified as an act of terrorism, as they can also be committed by criminals not associated with a terrorist organization. From 1990 to 1999 , a total of 153 cases of actual or threatened use of biological agents were reported, more than five times the reported cases for the time span from 1900-1989. "Threatened use" in this context refers to federal investigations that led to the seizure of biological agents with the intent of being used against civilians within the US, either by radicalized antigovernment groups or individuals. This significant increase in biological agents has been attributed to a rise in terrorist organizations that intentionally seek to inflict mass casualties and utilize intimidation tactics, criminal 
groups with fringe radical political, religious, or ecological reasons that want to raise awareness of a specific cause, or even governments that in the past have deployed biological agents to intimidate minorities or specific parts of the population either within or outside their territories.

Another term that is frequently associated with bioterrorism and biological agents used to cause mass casualties is weapons of mass destruction (WMDs). Despite the possibility of causing mass casualties, to date there have been no reported incidents where biological agents have been causatively linked to be used as WMDs. However, not all reported events involving biological agents are associated with a WMD that is targeting larger areas and intended to cause many casualties. In addition, a WMD is not exclusive to the use of biological agents, but rather encompasses the use of a chemical, nuclear, radiological, or biological weapon to inflict harm to a large population or damage to structures. The greatest concern for the use of a biological agent as a WMD relates to aerosol dissemination, which can be achieved if the particle size is in the range of $1-5 \mu \mathrm{m}$, which can penetrate into the lung bronchioles. It has been estimated that an aerosol dissemination of the plague (Yersinia pestis) or anthrax (Bacillus anthracis) over Washington, DC, could lead to the death of 1-3 million people given the right environmental conditions. ${ }^{2,3}$ Other routes of dissemination, such as through the water or food supply, are less likely, due to constant monitoring and significantly higher amounts of the biological agent required to cause harm or death. ${ }^{4}$

The complexity of a potential bioterrorism threat requires consideration of many different aspects. Broad classification of these aspects includes risk assessment involving monitoring and surveillance, risk management consisting of preparedness, prevention and decontamination, and risk communication based on public health policy and available resources (Figure 1). This review provides a brief perspective of all major aspects of a bioterrorism threat, focusing on risk assessment, management, and communication.

\section{History of bioterrorism and biological warfare}

Throughout history, the use of biological agents for warfare purposes has been reported. No matter if cadavers were used to spoil water supplies of enemies or even catapulting plague-infected corpses across walls to cause a mass exodus from a besieged city, ${ }^{5}$ the use of both pathogens and toxins to incapacitate and potentially cause significant mortality among the enemy has been used throughout human warfare. While pathogens are viable living organisms, such as bacteria and viruses, toxins are isolated chemicals from living organisms that are often more toxic (lower median lethal dose) than chemical warfare agents. ${ }^{6}$ Pathogens are able to reproduce, and therefore even small amounts can cause a significant threat to a larger population, while toxins often require ingestion or inhalation in significant amounts in order to affect a person. Historical use of biological agents was mainly limited to pathogens, due to the plague and cholera (Vibrio cholerae) being readily available and endemic to various parts of the world. ${ }^{7}$ While both the plague and cholera are not considered significant threats in the developed world, historical and present-day events indicate that the plague remains a deadly infection, while regional outbreaks of cholera remain common in parts of Asia and Africa. ${ }^{8}$ In more recent years, the primary biological agents that have been in the news are anthrax (B. anthracis) and

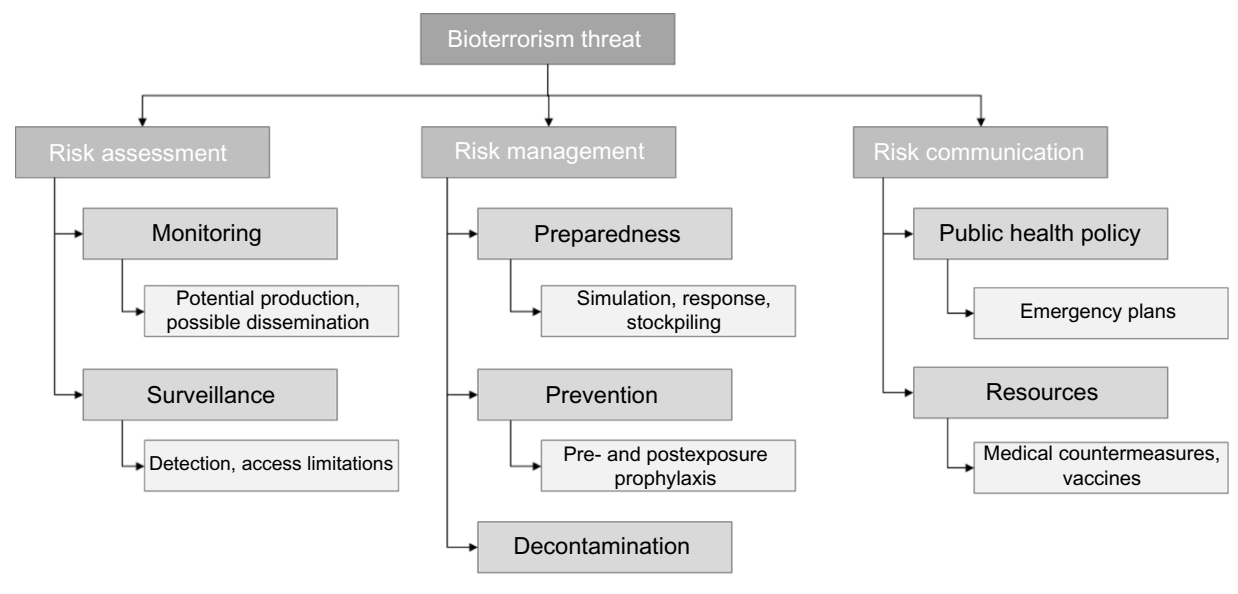

Research

Figure I Major areas of concern connected to a bioterrorism threat. Research in all areas remains a central requirement to advance all aspects. 
ricin (Ricinus communis). ${ }^{1}$ According to the US Centers for Disease Control and Prevention (CDC) classification, all category A agents, including anthrax and the plague, are of major concern for planners and risk management, since they are easily produced and dispensed. Anthrax spores are readily obtainable from both legitimate and illegitimate sources, while ricin is most commonly extracted from the seeds of the plant itself. Anthrax poses currently the highest threat based on models that simulate its dissemination in a dense urban area with 1 million inhabitants. According to a model by the World Health Organization, about 180,000 people will be at risk of exposure to anthrax spores, with an estimated 30,000 becoming incapacitated (affected by the agent and requiring medical care), while up to 95,000 deaths may occur. ${ }^{9}$ The next most devastating agent would be the plague, with 36,000 incapacitations and 44,000 estimated deaths. ${ }^{10}$ Such numbers may not be reflective of the current situation of a more suburban living situation.

The most commonly used and encountered pathogens and toxins (Table 1) are being monitored by various agencies around the globe, and have been added to the list of banned products by the Biological Weapons Convention. First enacted by the United Nations in 1975, the Biological Weapons Convention was signed by more than 160 states and 12 signatory states, banning the development, stockpiling, acquisition, retention, and production of biological agents intended for warfare purposes and weapons that aid in the dissemination of such agents. ${ }^{1,7,11}$

\section{Risk assessment}

With the increase in the use of biological agents over the past two decades comes an increased demand for risk assessment, monitoring, and surveillance. Risk assessment often involves modeling approaches that are based on certain assumptions. The four basic assumptions that can lead to an actual bioterrorism attack are that terrorists or criminals have 1) access to the agent, 2) the science and capabilities to manufacture and store the agent securely in sufficient amounts, 3) the ability to weaponize the agent for dissemination, and 4) the actual intent to use the agent, which will require an organizational leadership. ${ }^{1,7,12}$ Although biological agents that can be transmitted from person to person do not require weaponization and production on a mass scale, the agent needs to be obtained and delivered in a manner that matches the purpose of affecting as many people as possible. A distinction needs to be made between contagious agents (such as cholera, plague, smallpox, or typhus), which can be transmitted from person to person, and noncontagious agents (such as anthrax, botulism, tularemia, or ricin). The response to a contagious agent exposure would require a potential quarantine of the

Table I CDC classification of potential biological agents used for bioterrorism attacks

\begin{tabular}{|c|c|c|}
\hline Category $A$ agents & Category B agents & Category $\mathrm{C}$ agents \\
\hline $\begin{array}{l}\text { - Can be easily disseminated or transmitted } \\
\text { from person to person } \\
\text { - Result in high mortality rates and have the } \\
\text { potential for major public health impact } \\
\text { - Might cause public panic and social disruption } \\
\text { - Require special action for public health } \\
\text { preparedness }\end{array}$ & $\begin{array}{l}\text { - Are moderately easy to disseminate } \\
\text { - Result in moderate morbidity rates and } \\
\text { low mortality rates } \\
\text { - Require specific enhancements of the } \\
\text { CDC's diagnostic capacity and enhanced } \\
\text { disease surveillance }\end{array}$ & $\begin{array}{l}\text { - Are available } \\
\text { - Can be easily produced and disseminated } \\
\text { - Show potential for high morbidity and } \\
\text { mortality rates and major health impact }\end{array}$ \\
\hline Anthrax (Bacillus anthracis) & Brucellosis (Brucella species) & Emerging infectious diseases \\
\hline Botulism (Clostridium botulinum toxin) & Epsilon toxin (Clostridium perfringens) & Nipah virus \\
\hline Plague (Yersinia pestis) & $\begin{array}{l}\text { Food-safety threats (eg, Salmonella species, } \\
\text { Escherichia coli OI57:H7, Shigella) }\end{array}$ & Hantavirus \\
\hline Smallpox (Variola major) & Glanders (Burkholderia mallei) & \\
\hline Tularemia (Francisella tularensis) & Melioidosis (Burkholderia pseudomallei) & \\
\hline Viral hemorrhagic fever (eg, Ebola, Marburg, & Psittacosis (Chlamydia psittaci) & \\
\hline \multicolumn{3}{|l|}{ Lassa, Machupo) } \\
\hline & $\mathrm{Q}$ fever (Coxiella burnetii) & \\
\hline & Ricin toxin (Ricinus communis) & \\
\hline & Staphylococcal enterotoxin B & \\
\hline & Typhus fever (Rickettsia prowazekii) & \\
\hline & Viral encephalitis (eg, Venezuelan equine & \\
\hline & encephalitis, Eastern and Western equine & \\
\hline & encephalitis) & \\
\hline & Water-safety threats (eg, Vibrio cholerae, & \\
\hline & Cryptosporidium parvum) & \\
\hline
\end{tabular}

Abbreviation: CDC, Centers for Disease Control and Prevention. 
affected population with additional legal consequences. ${ }^{13}$ Large-scale quarantine measures have not been instituted in the US, although there is resource coordination in place as well as guidance from the $\mathrm{CDC}$ to prepare for potential bioterrorism emergencies. ${ }^{14}$

\section{Monitoring}

Risk assessment and monitoring of biological agent threats is more intricate and difficult than for chemical weapons, since the onset of symptoms can be delayed for hours, days, or weeks, and certain symptoms for specific pathogens and toxins are rather general and unspecific, hence delaying an initial diagnosis., ${ }^{412}$ Another component of risk assessment and surveillance is the epidemiological investigation following a confirmed case of a biological agent exposure. A delicate balance has to be found between investigating and informing the public, so that appropriate measures can be taken while at the same time preventing a public panic. . $^{10,15,16}$ A risk-management model has to encompass several probabilities associated with the specific agent to be used, the potential geographic location of an attack, and the level of preparedness and early intervention of communities and on the national level. ${ }^{4,12}$ Since no government has the resources to prevent a bioterrorism attack entirely, specific measures have to be taken to consider the most likely agent to be used, terrorist organization, criminals, or even governments being involved, and locations at risk. The final determination of the risk is then associated with the costs for monitoring and surveillance, vaccine or adequate treatment availability, economic impact, and casualty risk. ${ }^{1,17}$ Assessment of the location also has to consider what part of the population (politicians, scientists, people with specific abilities, general population) are being targeted.

The challenge in monitoring biological outbreaks is also dependent on the usual background noise within a given population when considering infections with viruses, such as influenza or the common cold. ${ }^{10,15}$ In this regard, the detection and determination of a biological agent dissemination may be delayed, depending on the incubation time, access to health care facilities, and location of the dissemination. If a biological agent is disseminated in a region with high background noise due to high seasonal influenza cases, then it is likely that more people will be exposed to the threat before appropriate public health measures can be instituted. ${ }^{18}$

\section{Surveillance}

Surveillance, even in urban areas, will mostly take the shape of epidemiological investigations as a consequence of an unusually high rate of infections and potential deaths among a specific population (either by geography, socioeconomic status, etc) or a sudden spike in similar symptom presentation with indications of an epidemic. ${ }^{19,20}$ Surveillance also needs to consider the potential response time and the incubation period before symptoms become apparent following exposure. In general, densely populated areas will be at greater risk of a bioterrorism attack, due to the higher exposure rate and easier dissemination.

Surveillance systems are currently implemented at the state level by the respective health departments, while the CDC has provided national guidelines for the syndromic surveillance by health professionals as well as rapid laboratoryscreening methods that allow for a faster response time. ${ }^{21}$ Such efforts are essential in order to decrease the potential spread of the disseminated agents and increase the survival rate of those that have been exposed to it.

\section{Risk management Preparedness}

Aside from surveillance and monitoring of a potential future bioterrorism attack, preparedness remains a central goal that requires constant improvement on the local, regional, and national levels. A report of the US General Accounting Office from 2005 indicates that in the year 2000, a total of $\$ 141.2$ million were spent on research efforts related to bioterrorism and terrorism, of which the CDC and the National Institutes of Health received the largest amounts, with $\$ 48.2$ and $\$ 43$ million, respectively. ${ }^{22}$ However, in the year 2001, the federal budget increased to a total of $\$ 156.8$ million. The allocation occurred before the terrorist attacks on the World Trade Center in September 2001 and the anthrax letters following shortly afterwards. Following the devastating terrorist attacks of September 11, 2001, funding significantly increased with the enactment of the Bioterrorism Act of 2002 to provide the CDC with additional resources to prepare states and the health care system adequately for a potential biological agent dissemination. ${ }^{23}$ The Department of Defense in 2002 had a budget for the chemical and biological defense program of $\$ 856$ million, which included $\$ 507$ million for research and development and $\$ 348$ million for procurement. ${ }^{24}$ In 2002, in response to the anthrax letters and potential other biological threats, the Health Resources and Services Administration was created, which was funded in 2006 with $\$ 460$ million to establish a national preparedness and response network among hospitals in collaboration with the CDC. Funding for the CDC also significantly increased to dedicate more resources toward bioterrorism preparedness and surveillance, 
with a budget of $\$ 766$ million in $2006 . .^{22,23}$ To this day, preparedness for a bioterrorism attack remains a challenge at the state and federal levels, mainly due to coordination of resources and establishing a network that optimizes state and federal resources to respond adequately and rapidly to an incident. ${ }^{25}$ Several federal and state agencies have established response plans and implemented new resources to prepare for a potential bioterrorism incident with guidance from the CDC and the Health Resources and Services Administration. Examples of such plans include training of hospital staff to recognize and respond to a potential biological agent exposure and prevent further contamination among the population at risk. This then also involves a statewide response to enact rapid communication and potentially quarantine for exposed individuals, while allowing the governor of the state to declare a public health emergency. This step then triggers federal agencies to offer additional resources, such as vaccinations, additional testing and epidemiological support, and medical assistance. The Federal Emergency Management Agency established the National Preparedness Guidelines in 2007 to respond to a potential hazard to include aerosolized anthrax, plague, and food contamination as biological attacks, among others. ${ }^{26}$

\section{Strategic stockpiling}

In the case of the dissemination of a biological agent and its detection, strategic stockpiles of vaccines as well as respective medication to treat the agent can be provided within less than 24 hours to an affected area. Each state within the US has established protocols and facilities where sufficient amounts of vaccines and antibiotics are being kept to supply the potentially affected population. ${ }^{26}$ In addition, there are several facilities across the nation, collectively referred to as the Strategic National Stockpile (SNS), which house vaccines and antibiotics for such events. Major metropolitan areas have established measures to ensure supply with needed medicine from the SNS to their communities through the Cities Readiness Initiative, which has now expanded to 72 participating cities across the US. ${ }^{27}$ Each of these areas has to be able to distribute and dispense appropriate medical countermeasures within 48 hours through dispensaries in the community. Manufacturers and vendors may also be able to supply an area rapidly with their existing inventory. What has been known as a push package is the rapid release of required drugs and treatments to the area in need from a SNS facility within 12 hours. While vaccines would serve mainly a preventative role, containing the spread of an infection from person to person, antibiotics serve the dual function of treatment and prevention. Several studies evaluated the role of contributing factors in reducing mortality following a biological agent exposure. The critical factors that have been evaluated are the ability to detect exposure earlier, increase local dispensing capacity and inventories, and national dispensing capacity. ${ }^{17,28}$ Early detection can only achieve a lower mortality rate if a rapid and high dispensing capacity can be achieved to contain and treat affected populations. If local inventory is low, then local dispensing capacity may not increase as rapidly as required. Strategic stockpiling also has to be considered within the framework of cost-effectiveness. Keeping inventory current and considering the turnover for renewing inventory would translate into a significant monetary amount to maintain stockpiling facilities that could respond to a biological agent attack on an urban area with more than 4 million people. In recent years, a more sophisticated approach has been suggested with shelf-life extension programs that aim to cycle necessary drugs through the stockpile before they expire in order to utilize them for nonemergency clinical use. ${ }^{29,30}$ Currently, a bioterrorism attack using anthrax spores on a city with 5 million people could result in the death of up to 200,000 people, assuming a direct exposure of 250,000 people if no stockpiles are available for distribution. Lowering this number is critically important to reduce mortality and prevent increased demand for prophylaxis by the nonexposed population. ${ }^{31}$

While current medical countermeasures are able to both prevent and treat some of the biological agents likely to be disseminated (such as anthrax, smallpox, botulism, plague, tularemia, and typhus), there a number of biological agents for which currently no effective treatment is available (including viral hemorrhagic fevers, such as Ebola and West Nile virus, and ricin). As mentioned, preventative measures should be considered first to limit the exposure and spread within the general population. However, effective postexposure prophylaxis (PEP) can reduce both morbidity and mortality rates, as well as prevent further spread of a contagious disease. PEP is currently available for anthrax, cholera, melioidosis, plague, Q fever, and smallpox, while there are no PEP treatments for botulism, equine encephalitis viruses, or ricin as of yet. ${ }^{32}$

\section{Preventative measures}

Prevention of a bioterrorist attack is a multimodal and multiagency approach that requires significant allocation of resources and incorporation of risk assessment and modeling to predict the potential impact of dissemination in specific areas. Prevention involves allocation of resources to intelligence agencies (Department of Homeland Security [DHS], 
Pentagon, Federal Bureau of Investigation, National Security Agency, etc) to monitor specific activities that could be related to a potential bioterrorism attack. This has to consider both national and international strategies to investigate and track activity related to diversion, manufacture, and trading of precursors necessary for bioterrorism agents as well as biological agents themselves. While there are a few nations that have been confirmed to manufacture and possess biological agents (North Korea, Iran, and Syria) there are a number of other nations that are suspected to be involved with trading and accumulating biological agents. ${ }^{1}$ The most likely source of a bioterrorism threat are not governments, though, but radicalized groups or individuals, both within the US or outside, that intend to utilize biological agents to cause mass casualties. Preventative measures by national and international agencies focus on tracking and disrupting such groups from obtaining and using biological agents. Most international groups are likely to collaborate with insiders, though, that are located within the country and region where the attack will take place. ${ }^{1,4}$ Prevention further extends to restricting access to biological agents and their precursors, as well as monitoring of facilities that have the capabilities to culture and manufacture such agents. This approach has the limitation that diversion of bacterial agents and their products (botulinum toxin from Clostridium botulinum), as well as plant products (ricin from $R$. communis), is relatively easy without raising suspicion, due to bacterial cultures replenishing fast and the content of ricin being variable and considered a waste product in the generation of castor oil, which is commonly used in the cosmetics industry. Prevention also incorporates a sentinel laboratory system that can detect biological agents readily and alarm local, state, and federal authorities to contain a potential outbreak. These laboratories are part of the Laboratory Response Network, which is organized into approximately 25,000 commercial and private sentinel laboratories for initial detection of potential biological agents, which is then confirmed by over 150 reference laboratories across the nation. Finally, national laboratories within the CDC or the military will handle specific strain investigations, and are even able to trace the strain back to a particular laboratory or facility in or outside the US. ${ }^{28,33}$ Another program that provides for an early detection system is BioWatch, which was instituted by the DHS in collaboration with the Environmental Protection Agency (EPA) to continuously monitor air quality in metropolitan areas for potential pathogens via polymerase chain reaction. While samples were initially sent to a federal facility in California, most state and public health laboratories conduct the analysis now, which provides a faster reporting and response time. ${ }^{23}$ One issue that may compromise the current setup of the BioWatch program is staffing issues that impact resource availability for timely and continuous monitoring, especially if an acute outbreak (eg, seasonal influenza, West Nile virus, etc) competes for the same resources. Currently, there are no attempts to increase funding or resource allocation to the BioWatch program.

In contrast, funding for vaccines and treatment options in response to the dissemination of a biological agent has mainly focused on anthrax, tularemia, smallpox, and ricin, while other agents have been underfunded. A government-funded initiative called BioShield was established in 2004 to provide funds and spur private sector research and procurement of appropriate medical countermeasures to category A biological agents. The project was allocated $\$ 5.6$ billion, and has added new PEP to the SNS, while the development of new treatments - both vaccines and small molecules - has been rather slow and modest in scope. ${ }^{34} \mathrm{~A}$ live smallpox vaccine is available from the CDC and may be distributed to affected areas, although the live vaccine is associated with side effects that have to be considered before application. ${ }^{35}$ At the same time, access to these agents has been significantly restricted to prevent diversion for illegal use. The CDC together with the National Institute of Allergy and Infectious Diseases is tasked with limiting access to category A agents to research institutions that can house a biosafety level 4 facility (currently, there are only 15 biosafety level [BSL]-4 facilities in the US, and nine are federal laboratories). This has created an environment where researchers who wish to conduct research with these agents (commonly referred to as dual-use agents) to further our understanding of how best to treat infections or exposure to them are limited due to inaccessibility to these agents. ${ }^{36}$

\section{Environmental decontamination measures}

Upon dissemination of a biological agent, once it has been detected either through surveillance and/or epidemiological methods, treatment of patients and containment of infection is of primary concern. This will involve to some degree determination of the actual exposure area in terms of location (indoors or outdoors), access (restricted or open to the public), duration from dissemination (potential population that has been exposed), and nature of the agent (airborne particles, solid, fume, etc). These parameters will also determine the necessary steps in decontaminating the environment. ${ }^{17,37}$ Since anthrax is considered the most likely agent to be disseminated, research on decontamination methods has been 
skewed heavily in this direction. Though several biological agents can remain viable in the environment for an extended period of time, lasting from hours to days (eg, ricin, botulinum toxin), anthrax spores can persist in the environment for months or even years, which requires careful evaluation of the decontamination process. ${ }^{38}$ In general, the steps involved in decontamination involve the initial analysis of samples to determine the agent and the exposed area, followed by containment and potential quarantine to avoid further distribution of the agent. Both of these steps are already associated with significant consideration as to the environment and how effective sampling is performed. For a more rapid evaluation, fewer samples will be needed but a potentially uncontaminated area may have to be sealed off as well, which raises the concerns of the public. The $\mathrm{CDC}$ has established guidelines for appropriate sampling in anthrax-dissemination cases, which were utilized to guide environmental sampling following the anthrax letters sent in $2001 .{ }^{37}$ The contaminated area may also require different treatment approaches if the surfaces are porous or nonporous. ${ }^{39}$ In many situations, it will be necessary to remove porous surface items and incinerate them, while in other cases (especially with items of value) they may be decontaminated together with the surrounding environment if they can withstand the chemical exposure. ${ }^{40}$ The most common method of decontamination is sealing off the affected area and treating it with a gaseous sporicide, such as chlorine dioxide, vaporized hydrogen peroxide, ethylene oxide, or paraformaldehyde. ${ }^{37,40}$ All of these agents have been used successfully in decontamination of mailing facilities in the US, as well as in drumming incidents where anthraxcontaminated animal skins led to small-scale dissemination of spores. ${ }^{37}$ Following decontamination, confirmatory sampling is necessary to determine successful removal of the agent. Another aspect of fumigating the contaminated environment is establishing public trust in the process, which would likely not be as high following surface-cleaning decontamination.

Since decontamination methods to date have been rarely used on a larger scale, only a few agencies were involved in coordinating the response and remediation process in regard to the dissemination of anthrax. On the federal level in the US, the EPA is the responsible agency to oversee the decontamination process in consultation with the CDC. When initial determination of the source is being investigated, it is essential to investigate if the resulting cases were a targeted and coordinated dissemination of a biological agent or the consequence of natural exposure (as was the case with the dried animal skins used to make drums, contamination of wounds with C. botulinum, or exposure to animals infected with $Y$. pestis). Epidemiological studies will then assist in the determination of the source of an outbreak.

An as-yet mainly unexplored and unanswered component of environmental decontamination is waste disposal. In the process of immediate and long-term recovery from a biological agent attack, officials have to consider the safe and timely removal of contaminated waste, most of which will have to be handled separately and incinerated if it cannot be decontaminated, as explained earlier. Through a series of workshops, a research team sought to provide the current state of organization and knowledge following a bioterrorism attack in regard to waste disposal. ${ }^{41}$ What became clear is that no strategy has been established to date that provides for a framework of how to dispose of waste contaminated with a biological agent. Following decontamination on site, it remains unclear if such waste can be disposed of in a regular landfill environment or require specific handling. Furthermore, it appears unclear when waste would be considered to be entirely decontaminated and considered "clean". The workshop participants therefore recommended a regulatory framework from the federal government about the classification of such waste and its recommended disposal method. There is consensus that further research is necessary to address the issue of waste contaminated with a biological agent and evaluation of risk assessment related to decontamination, transportation, and final disposal. ${ }^{41}$

\section{Risk communication Public health policy}

The response to the dissemination of a biological agent involves a concerted effort by local, state, and federal agencies and stakeholders that have been trained appropriately. Ongoing efforts to optimize the response time and train first responders (police, emergency-response personnel, public health department officials) to recognize the potential involvement of a biological agent remain a priority to initiate appropriate surveillance, allocation of resources, and containment of the source outbreak. ${ }^{17}$ Since many biological agents may present with delayed and unspecific symptoms, there is a lag time in the response, which will likely be initiated by primary care physicians, physician's assistants, nurses, or hospitals. ${ }^{42}$ Two critical areas should therefore be considered in the response to a bioterrorism attack: 1) adequate training of health care professionals to detect and respond to a potential biological agent exposure, and 2) access to health care facilities for the public at large. 
The earlier the causative agent can be identified, the faster the response time and potential containment of the outbreak will be. While monitoring and surveillance for potential biological agents has been implemented by the EPA and DHS in large metropolitan areas that are considered a primary target due to high population density, there is no reason that other parts of the country could not be affected. In such cases, training of health care providers will be critical to the outcome and reducing morbidity and mortality. Since implementation of the Hospital Preparedness Program (HPP) by the US Department of Health and Human Services in 2002, several local and regional coalitions of hospitals, health care providers, and agency representatives have been established. ${ }^{33}$ Such coalitions seek to prepare a community for a potential bioterrorism attack, share resources, establish a protocol to follow, and optimize communication among participating facilities to respond to a mass-casualty event as effectively as possible (Figure 2). ${ }^{43}$ Examples of health care coalitions that have been well established are Los Angeles, New York City, Seattle and King County, and Minneapolis. All of these coalitions were established and are maintained with funding from the HPP, work by assigning core hospitals with resources to serve as a disaster-response center, and communicate and coordinate with surrounding hospitals to allocate resources, bed capacity, additional staffing, and required medications. However, new and existing coalitions are faced with a range of challenges, despite the importance of maintaining them. Among these challenges, sharing of proprietary information (bed status and capacity), insufficient funding for resources and staffing, geographic limitations (differing regional boundaries for coalitions beyond counties, states, and federal regions), and allocation and continued renewal of HPP grants require further improvement and research.

As mentioned before, training of health care professionals in disaster preparedness and response is an essential component in detecting the dissemination of a biological agent and initiating appropriate treatment and containment. If a biological agent attack occurred, a regional call will likely try to mobilize all available resources - including health care professionals, emergency staff, and local and regional response management. Responding to a mass-casualty event will require the willingness of health care professionals to engage instead of staying with their family. In a study, health care workers were asked about their willingness to respond to a range of natural and terrorist-associated mass-casualty events. ${ }^{44}$ Eight local health departments - four rural and four

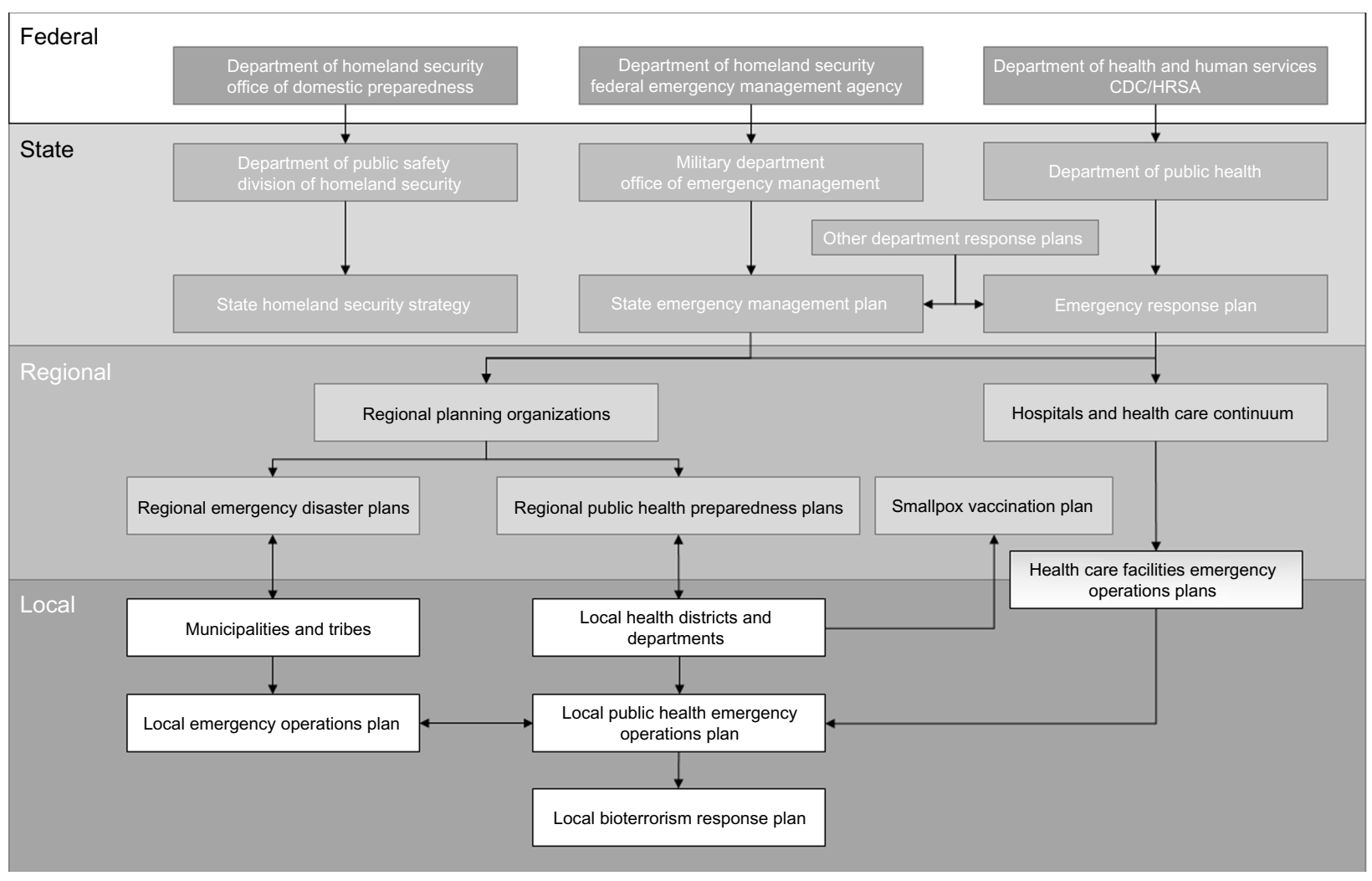

Figure 2 Federal, state, regional, and local agency involvement in a potential biological attack. At all levels, established emergency-response plans should be in place. Abbreviations: CDC, Centers for Disease Control and Prevention; HRSA, Health Resources and Services Administration. 
urban - were asked about their willingness to respond via survey. For a bioterrorist attack involving anthrax dissemination, $22 \%-48 \%$ of survey respondents stated they were unwilling to respond to the event regardless of severity. This reflects a serious issue facing the response willingness of health care workers, and one major conclusion of the study was to educate and train workers to better prepare them for a potential bioterrorism attack.

In summary, public health policy and community engagement remain topics that require further research and awareness of all stakeholders. Aside from public health agencies, health care facilities and businesses will also be involved in the response coordination following a bioterrorism attack. Increased preparedness through training and establishment of coalitions will be an essential part of public health policy. Public awareness should be carefully balanced to not cause panic, but at the same time prepare the public for a potential mass-casualty event. Past events involving natural disasters, as well as bioterrorism threats, indicate that mortality and morbidity can be decreased if an established protocol is in place that enables first responders, hospitals, and public officials to direct the public.

\section{Prospects and future perspectives}

Based on our past experiences with mass-casualty events and the use of biological agents in bioterrorism attacks, current surveillance and preparedness should remain the focus of further improvement and research. Detection of the dissemination of a biological agent, either through sentinel air-measurement devices in metropolitan areas or epidemiological investigations to initiate the response, are of critical importance. The earlier a dissemination is detected, the faster the response time and the lower the morbidity and mortality rates. This requires significant awareness by public health departments and health care workers and ongoing training to provide adequate symptom evaluation and treatment approaches. With the main focus of prevention centered on anthrax, plague, smallpox, and tularemia, which are category A agents, it remains imperative to inform the public and health care workers about the potential for other agents, such as ricin, which can be easily disseminated. Although a vaccine for anthrax is available (anthrax vaccine adsorbed), it is associated with side effects and requires six to seven doses for sufficient immunity, which limits its use in vaccinating the general public (which will often only receive three doses). ${ }^{45}$ The current SNS contains 10 million doses of anthrax vaccine in case of a widespread anthrax bioterrorism attack. Aside from preventative measures, treatment approaches for anthrax and the plague include antibiotics, which are also part of the SNS, to prevent infection, PEP, and for the long-term treatment of exposed populations. One critical point is the availability of intravenous antibiotics for the treatment of acutely ill patients following an anthrax or other biological agent attack.

Moving forward, it is critical to remain vigilant about potential bioterrorism attacks and rather consider proactive than reactive measures. Only after the anthrax letters in 2001 did the US and other nations realize what current shortcomings exist, and significant investment has been made to remedy some of them through increased surveillance, awareness, and preparedness. However, most of the current measures are based on incidents limited to a specific area, such as a metropolitan dissemination that could be remedied through coordination among few state and federal agencies. We currently do not have the optimal tools to provide us with the impact of multiple concurrent large-scale bioterrorism attacks and which steps would be crucial in response to them. Of primary importance for the near future remain surveillance and preparedness to detect and respond to the dissemination of a biological agent. The legitimate desire of researchers to improve response and develop new treatments for biological agents (for some, we do not have any treatment options aside from supportive care, eg, ricin) needs to be weighed against a potential diversion of agents, and may require strict regulations that still allow for access if specific requirements (BSL-3 or BSL-4 laboratory, access limitations, monitoring of personnel, etc) are being met.

Widespread surveillance through biosensoring technology is becoming a more realistic and financially feasible goal that should be pursued at the regional, state, and federal levels. In some instances, collection of samples and reporting of results may be crucial (eg, during a major sporting event where dissemination may lead to secondary infections far away from the original source) to prevent secondary contaminations. There are mobile rapid-screening units available that allow for the preliminary detection of biological agents, and such devices may soon become more frequently used.

Finally, an as-yet unresolved issue is emerging pathogens and biological toxins. While the CDC's category A biological agents remain the most likely to be disseminated at this time, little is known about new bacterial strains or viruses that may be utilized by larger organizations against a nation or population. The intelligence community has to be aware and should monitor such potential developments, since we currently have no effective response or even ability to detect some of these agents. 


\section{Disclosure}

The author reports no conflicts of interest in this work.

\section{References}

1. Carus SW. Bioterrorism and Biocrimes: The Illicit Use of Biological Agents since 1900. Amsterdam: Fredonia; 2002.

2. Inglesby TV, Henderson DA, Bartlett JG, et al. Anthrax as a biological weapon: medical and public health management. Working Group on Civilian Biodefense. JAMA. 1999;281(18):1735-1745.

3. Inglesby TV, Dennis DT, Henderson DA, et al. Plague as a biological weapon: medical and public health management. Working Group on Civilian Biodefense. JAMA. 2000;283(17):2281-2290.

4. Radosavljevic V, Belojevic G. A new model of bioterrorism risk assessment. Biosecur Bioterror. 2009;7(4):443-451.

5. Smart JK. History of chemical and biological warfare: an American perspective. In: Sidell FR, Takafuji ET, Franz DR, editors. Medical Aspects of Chemical and Biological Warfare. Washington DC: Borden Institute, Walter Reed Army Medical Center; 1997:9-86.

6. Szinicz L. History of chemical and biological warfare agents. Toxicology. 2005;214(3):167-181.

7. Eitzen EM Jr. Reducing the bioweapons threat: international collaboration efforts. Public Health Rep. 2001;116 Suppl 2:17-18.

8. Snowden FM. Emerging and reemerging diseases: a historical perspective. Immunol Rev. 2008;225:9-26.

9. World Health Organization. Health Aspects of Chemical and Biological Weapons. Geneva: WHO;1970.

10. Parnell GS, Smith CM, Moxley FI. Intelligent adversary risk analysis: a bioterrorism risk management model. Risk Anal. 2010;30(1):32-48.

11. Karwa M, Currie B, Kvetan V. Bioterrorism: preparing for the impossible or the improbable. Crit Care Med. 2005;33(Suppl 1):S75-S95.

12. Pappas G, Panagopoulou P, Akritidis N. Reclassifying bioterrorism risk: are we preparing for the proper pathogens? J Infect Public Health. 2009;2(2):55-61.

13. Barbera J, Macintyre A, Gostin L, et al. Large-scale quarantine following biological terrorism in the United States: scientific examination, logistic and legal limits, and possible consequences. JAMA. 2001; 286(21):2711-2717.

14. Centers for Disease Control and Prevention. Preparation and planning for bioterrorism emergencies. 2013. Available from: http://www.bt.cdc. gov/bioterrorism/prep.asp. Accessed September 1, 2014.

15. McBrien KA, Kleinman KP, Abrams AM, Prosser LA. Use of outcomes to evaluate surveillance systems for bioterrorist attacks. BMC Med Inform Decis Mak. 2010;10:25.

16. Born CT, Briggs SM, Ciraulo DL, et al. Disasters and mass casualties: II. Explosive, biologic, chemical, and nuclear agents. JAm Acad Orthop Surg. 2007;15(8):461-473.

17. Raber E, Hibbard WJ, Greenwalt R. The national framework and consequence management guidance following a biological attack. Biosecur Bioterror. 2011;9(3):271-279.

18. Cheng KE, Crary DJ, Ray J, Safta C. Structural models used in realtime biosurveillance outbreak detection and outbreak curve isolation from noisy background morbidity levels. J Am Med Inform Assoc. 2013;20(3):435-440.

19. Tyshenko MG. Management of natural and bioterrorism induced pandemics. Bioethics. 2007;21(7):364-369.

20. Hendrickson RG, Hedges JR. Introduction - what critical care practitioners should know about terrorism agents. Crit Care Clin. 2005;21(4):641-652, v.

21. Centers for Disease Control and Prevention. Bioterrorism preparedness and response. Available from: http://emergency.cdc.gov/bioterrorism. Accessed June 6, 2014.

22. Sell TK, Watson M. Federal agency biodefense funding, FY2013FY2014. Biosecur Bioterror. 2013;11(3):196-216.

23. Ziskin LZ, Harris DA. State health policy for terrorism preparedness. Am J Public Health. 2007;97(9):1583-1588.
24. Johnson-Winegar A. Biological Terrorism: Department of Defense Research and Development. In: Defense Do, editor. Washington: United States Congress; 2002. Available from: http://biotech.law.lsu.edu/blaw/ DOD/ajwstatement.pdf. Accessed September 25, 2014.

25. Bravata DM, Zaric GS, Holty JE, et al. Reducing mortality from anthrax bioterrorism: strategies for stockpiling and dispensing medical and pharmaceutical supplies. Biosecur Bioterror. 2006;4(3):244-262.

26. Federal Emergency Management Agency. National preparedness guidelines. 2007. Available from: http://www.fema.gov/pdf/ emergency/nrf/National_Preparedness_Guidelines.pdf. Accessed September 1, 2014.

27. Centers for Disease Control and Prevention. Cities Readiness Initiative. 2013. Available from: http://www.cdc.gov/phpr/stockpile/cri/index.htm. Accessed September 1, 2014.

28. Hook-Barnard I, Posey Norris SM, Alper J. Technologies to Enable Autonomous Detection for BioWatch, Ensuring Timely and Accurate Information for Public Health Officials. Washington: National Academies; 2014.

29. Esbitt D. The Strategic National Stockpile: roles and responsibilities of health care professionals for receiving the stockpile assets. Disaster Manag Response. 2003;1(3):68-70.

30. Courtney B, Easton J, Inglesby TV, SooHoo C. Maximizing state and local medical countermeasure stockpile investments through the ShelfLife Extension Program. Biosecur Bioterror. 2009;7(1):101-107.

31. Zaric GS, Bravata DM, Cleophas Holty JE, McDonald KM, Owens DK, Brandeau ML. Modeling the logistics of response to anthrax bioterrorism. Med Decis Making. 2008;28(3):332-350.

32. Ramasamy S, Liu CQ, Tran H, et al. Principles of antidote pharmacology: an update on prophylaxis, post-exposure treatment recommendations and research initiatives for biological agents. Br J Pharmacol. 2010;161(4):721-748.

33. Courtney B, Toner E, Waldhorn R, et al. Healthcare coalitions: the new foundation for national healthcare preparedness and response for catastrophic health emergencies. Biosecur Bioterror. 2009;7(2):153-163.

34. Cohen J. Biodefense: 10 years after. Reinventing Project BioShield. Science. 2011;333(6047):1216-1218.

35. Institute of Medicine Committee on Smallpox Vaccination Program I. Review of the Centers for Disease Control and Prevention's Smallpox Vaccination Program Implementation: Letter Report 2. Washington: National Academies; 2003.

36. Dubov A. The concept of governance in dual-use research. Med Health Care Philos. 2014;17(3):447-457.

37. Pottage T, Goode E, Wyke S, Bennett AM. Responding to biological incidents - what are the current issues in remediation of the contaminated environment? Environ Int. 2014;72:133-139.

38. Cole LA. Persistence of a mock bio-agent in cross-contaminated mail and mailboxes. J Public Health Manag Pract. 2003;9(5):357-360.

39. Franco C, Bouri N. Environmental decontamination following a largescale bioterrorism attack: federal progress and remaining gaps. Biosecur Bioterror. 2010;8(2):107-117.

40. Wood JP, Blair Martin G. Development and field testing of a mobile chlorine dioxide generation system for the decontamination of buildings contaminated with Bacillus anthracis. J Hazard Mater. 2009;164(2-3):1460-1467.

41. Lesperance AM, Stein S, Upton JF, Toomey C. Challenges in disposing of anthrax waste. Biosecur Bioterror. 2011;9(3):310-314.

42. Pinto VN. Bioterrorism: health sector alertness. J Nat Sci Biol Med. 2013;4(1):24-28.

43. Fuse A, Okumura T, Hagiwara J, et al. New information technology tools for a medical command system for mass decontamination. Prehosp Disaster Med. 2013;28(3):298-300.

44. Barnett DJ, Thompson CB, Errett NA, et al. Determinants of emergency response willingness in the local public health workforce by jurisdictional and scenario patterns: a cross-sectional survey. BMC Public Health. 2012;12:164.

45. Bienek DR, Loomis LJ, Biagini RE. The anthrax vaccine: no new tricks for an old dog. Hum Vaccin. 2009;5(3):184-189. 
Risk Management and Healthcare Policy

Dovepress

\section{Publish your work in this journal}

Risk Management and Healthcare Policy is an international, peerreviewed, open access journal focusing on all aspects of public health, policy, and preventative measures to promote good health and improve morbidity and mortality in the population. The journal welcomes submitted papers covering original research, basic science, clinical \& epidemio- logical studies, reviews and evaluations, guidelines, expert opinion and commentary, case reports and extended reports. The manuscript management system is completely online and includes a very quick and fair peerreview system, which is all easy to use. Visit http://www.dovepress.com/ testimonials.php to read real quotes from published authors.

Submit your manuscript here: http://www.dovepress.com/risk-management-and-healthcare-policy-journal 